\title{
A case report of open appendectomy in treating acute perforated appendicitis with necrotizing fasciitis of the abdominal wall: a rare complication of a common disease*
}

\author{
Rezvan Hosseinzadeh ${ }^{1}$, Mohsen Rakhsha ${ }^{2}$, Kataneh kazemi ${ }^{2}$, and Morteza behnamfar ${ }^{2}$ \\ ${ }^{1}$ Babol University of Medical Science \\ ${ }^{2}$ North Khorasan University of Medical Sciences
}

September 25, 2021

\begin{abstract}
We present a case of a 37-year-old woman referred to our hospital with a 1-week history of significant weakness, anorexia, and mild abdominal pain. According to laboratory and radiographic data, the patient was diagnosed with perforated appendicitis and gangrene.
\end{abstract}

\section{Hosted file}

Manuscript.docx available at https://authorea.com/users/437588/articles/539117-a-casereport-of-open-appendectomy-in-treating-acute-perforated-appendicitis-with-necrotizingfasciitis-of-the-abdominal-wall-a-rare-complication-of-a-common-disease 

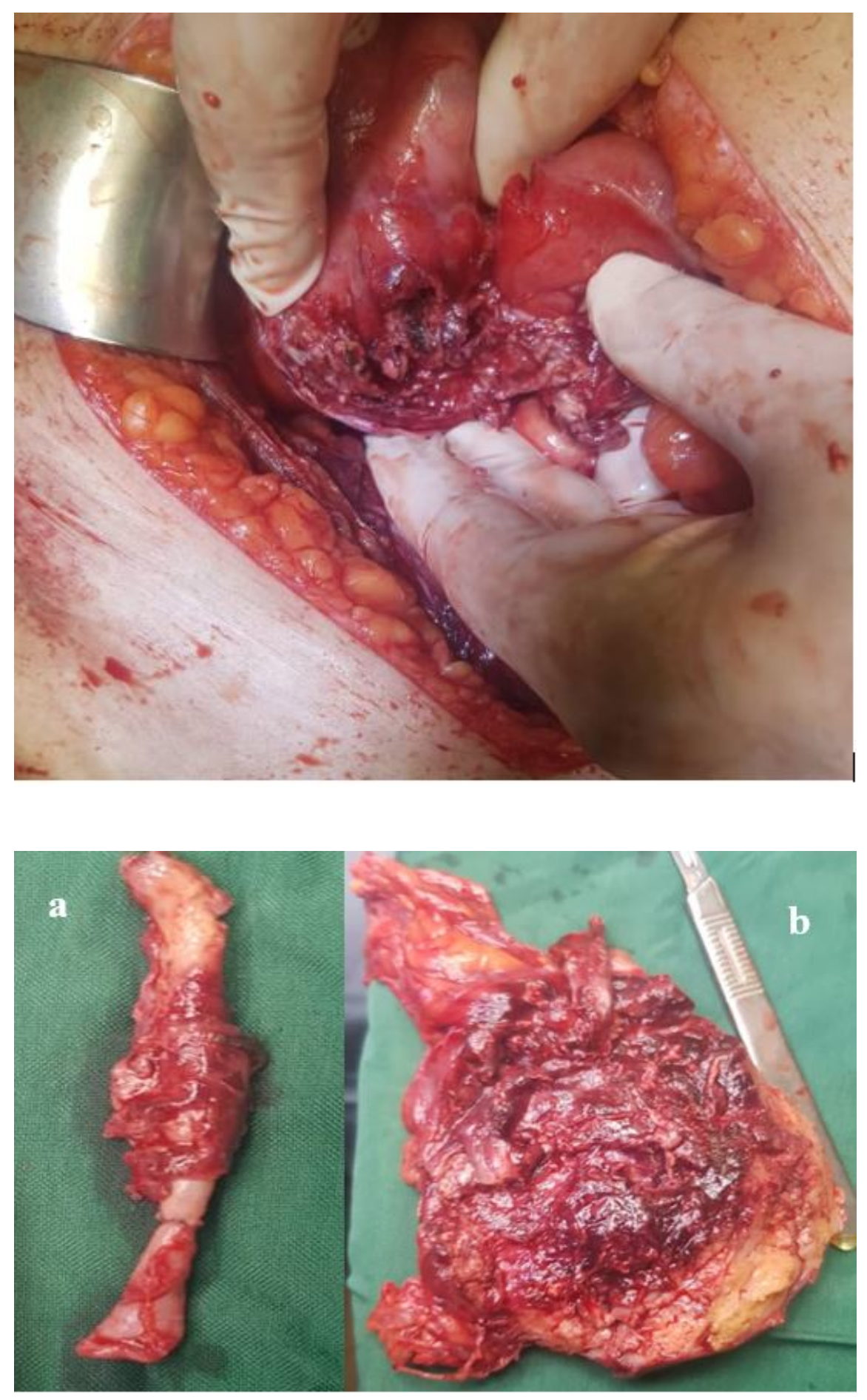